\title{
Mode of Algicidal Action and Microscopic Observations of Algicidal Process
}

\author{
Seong-Yun Jeong \\ Department of Biomedical Science \\ Daegu Catholic University \\ Gyeongsan 38430 \\ Korea
}

\begin{abstract}
A total of 130 bacterial isolates were isolated for this study. Three isolates showed algicidal activity against A. catenella, C. marina, and C. polykrikoides. Isolate DC-11 showed algicidal activity (95\%) against A. catenella. Isolate DC-43 exhibited the strongest algicidal activity (98\%) against A. catenella. Isolate DC-43 showed strong algicidal activity (93\%) against $C$. polykrikoides. Isolate DC-49 exhibited the strongest algicidal activity (97\%) against C. marina. The results using commercially available tissue culture inserts revealed that Arthrobacter sp. DC-11, Brachybacterium sp. DC-43, and Bacillus sp. DC-49 killed HAB species through algicide release, as an indirect attacker. The algicidal effects of three isolates against three algal cells were observed under light microscope during the algicidal process.
\end{abstract}

Keywords: Algicidal bacterium, Algicidal activity,Harmful algal blooms (HABs), Mode of algicidal action

\section{Introduction}

The planktonic microalgae of the world's oceans are critical food source for shellfish and the larvae of crustaceans and finfish (Sarthouet al., 2005). Microalgae are beneficial for aquaculture and wild fisheries operations. However, blooms of red tide can have a negative effect (Hallegraeff, 1995). Some toxic microalgae produce toxins and kill cultivated fish. Sometimes, microalgal toxinsare accumulated in filter-feeding shellfish and have a negative impact on human activities; therefore, algal blooms so-called 'harmful algal blooms (HABs)'. The term 'red tide' is a common name of algal blooms. However, discoloration of the water might be of other various colors - white, blue, green, brown or purple and red tide causes no negative effects. Therefore, scientists have used the term HABs since it was introduced for the first time in 1974.

Globally, HABs have severed economic losses and serious human health problems as well as damage of marine ecosystem (Anderson et al., 2000; Nagayama et al., 2003). It is guessed that the economic loss of a HABs is usually over millions of US dollars (GEOHAB, 2001). In order to mitigate the harmful effects of HABs efficiently, it is imperative to develop new prevention methods for HABs (Su et al., 2007). In marine and freshwater ecosystems, biological agents such as bacteria, viruses, protozoans, and fungi have all shown promise as potential algal bloom suppressors (Kang et al., 2005).

Biological control implies the use of organisms or pathogens to remove HABs. Biological agents are advantageous compared with other control methods of HABs (Mitsutaniet al., 2001). Because most of them are isolated from ocean, that exist as native organisms in the HABs environments (Nagasaki et al., 2000). Researches into the relationship between bacteria and algae have resulted in the isolation of several strains of bacteria capable of inhibiting or killing harmful algal bloom (HAB) species (Kitaguchiet al., 2001). More research is clearly needed to pursue the possibility that bacteria can be important in controlling HABs (Amaroet al., 2005).

\section{Materials and Methods}

\subsection{Algal cultures and screening of algicidal bacteria}

Algal cultureswere supplied by the National Fisheries Research \& Development Institute (NFRDI), Republic of Korea. Algal cells belong to Dinophyceae were maintained in an f/2-Si medium (Guillard and Ryther, 1962) at 20 ${ }^{\circ} \mathrm{C}, \mathrm{pH} \mathrm{8.0,}$ with cycles consisting of $12 \mathrm{~h}$ of darkness and $12 \mathrm{~h}$ of cool white fluorescent light. Water samples were collected from coastal surface water in Pusan, Republic of Korea. Samples were serially diluted and $0.1 \mathrm{~m} \ell$ aliquots of each dilution were spread onto PPES-II (Taga, 1968) agar plates, followed by incubation for seven days at $20^{\circ} \mathrm{C}$. Individual colonies of distinct morphology were streaked onto PPES-II agar plates for purification and frozen at $-70^{\circ} \mathrm{C}$ in $20 \%$ glycerol. 
In experiments testing bacterial effects against algal cultures, it was used 24 -well plates. Each well contained $1 \mathrm{~m} \ell$ of algal culture, to which $0.5 \mathrm{~m} \ell$ of a bacterial culture filtrate had been added. The plates were monitored at a magnification of $\times 200$ or $\times 400$. The bacterial isolates exhibiting algicidal activity against Alexandrium catenella, Chattonella marina, and Cochlodinium polykrikoides were selected for further study.

\subsection{Determination of mode of algicidal action}

One method to test for dissolved algicides involves incubating the algal species and the algicidal bacteria, physically separated via commercially available tissue culture inserts according to the Kim et al. (1999). This protocol was carried out with 24-well plates (Fig. 1). Tissue culture inserts of $0.4-\mu \mathrm{m}$ pore size were added to each well, and $1 \mathrm{~m} \ell$ of algal culture $\left(1.0 \times 10^{4}\right.$ cells $\left./ \mathrm{m} \ell\right)$ was inoculated into the inside of each insert. Each well was tested as follows: (A) PPES-II medium added between well and insert, (B) bacterial culture added between well and insert, and (C) bacterial culture added to the inside of each insert. Equal volumes $(200 \mu \ell)$ of PPES-II medium and bacterial culture were added to each well. The plates were cultured in algal culture conditions, as described above.

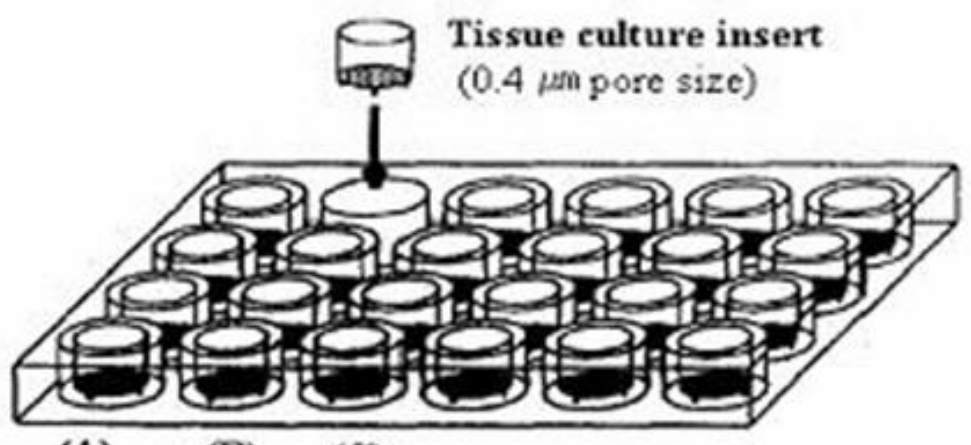

(A) (B) (C)

(A)

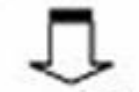

(B)

(C)

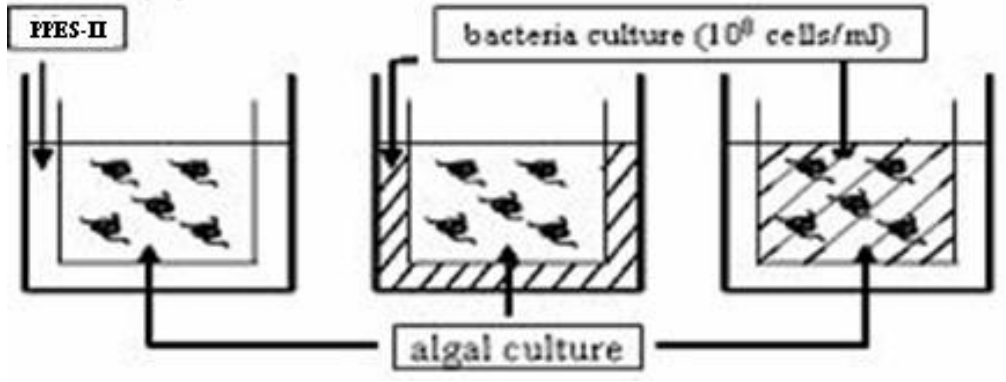

Fig. 1. Experimental procedure for determination of algicidal mode of algicidal bacteria, using commercially available tissue culture inserts (0.4- $\mu \mathrm{m}$ pore size). One milliliter of algal culture was inoculated into each tissue culture insert of the 24-well plates. (A) PPES-II medium was added between the well and the tissue culture insert, (B) bacterial culture was added between the well and the tissue culture insert, and (C) bacterial culture was added to the inside of the tissue culture insert.

\subsection{Impact and algicidal activity of algicidal bacteria culture filtrates against algal cultures}

After cultivation on PPES-II, bacterial cultures were centrifuged at $8,000 \times g$ for 20 min the filtrates were then filtered through $0.2-\mu \mathrm{m}$ membranes. The algicidal activity of the bacterial culture filtrates against algal cultures $\left(1.0 \times 10^{4}\right.$ cells/m $\ell$ ) were tested using 24-well plates. Each well contained $1 \mathrm{~m} \ell$ of algal culture, to which $500 \mu \ell(\mathrm{v} / \mathrm{v})$ of culture filtrates were added. The plates were monitored at a magnification of $\times 200$, depending on the size of the organism being tested. Several transects of each well were inspected, and the condition of the algae was noted. The plates were inspected every $2 \mathrm{~h}$ for the first $7 \mathrm{~h}$, and then less frequently over the next two days.

The algicidal activity of isolate strains was calculated, using the following equation (Kim et al., 2007): Algicidal activity $(\%)=(1-\mathrm{Tt} / \mathrm{Ct}) \times 100$. $\mathrm{Tt}$ (treatment) and $\mathrm{Ct}$ (control) are the cell concentrations of algal culture with bacterial culture filtrates, and sterile PPES-II broth, respectively, after inoculation time $(\mathrm{t})$. 
To observe morphology change of algal cells, a suitable volume (10\%) of the culture filtrates was inoculated to the cultures of algal species the treatment and was observed under light microscope. In the case of control, equal volumes of sterile PPES-II broth were added to the algal cultures in the treatment instead of bacterial culture filtrates.

\section{Results}

\subsection{Screening of algicidal bacteria}

A total of 130 bacterial isolates were isolated. Three isolates showed algicidal activity against A. catenella, C. marina, and $C$. polykrikoides. The algicidal activities of three algicidal isolates against three algal species were investigated. Isolate DC-11 showed algicidal activity (95\%) against $A$. catenella. Isolate DC-43 exhibited the strongest algicidal activity (98\%) against $A$. catenella. Isolate DC-43 showed strong algicidal activity (93\%) against C. polykrikoides. Strain DC-49 exhibited the strongest algicidal activity (97\%) against $C$. marina (Table 1).

Table 1. Algicidal activity of isolated strains against $A$. catenella, $C$. marina, and $C$. polykrikoides

\begin{tabular}{llll}
\hline & Alexandrium catenella & Chatonella marina & Cochlodinium polykrikoides \\
\hline Isolate DC-11 & $95 \%$ & $90 \%$ & $75 \%$ \\
Isolate DC-43 & $98 \%$ & $94 \%$ & $93 \%$ \\
Isolate DC-49 & $80 \%$ & $97 \%$ & $79 \%$ \\
\hline
\end{tabular}

\subsection{Mode of action of DC-11, DC-43, and DC-49}

The results using commercially available tissue culture inserts revealed that Arthrobacter sp. DC-11, Brachybacterium sp. DC-43, and Bacillus sp. DC-49 killed HAB species through algicide release, as an indirect attacker. Each (A), (B), and (C) well showed negative, positive, and positive, respectively, where a negative result means there was no algicidal activity and a positive result means there were signs of algicidal activity.

\subsection{Impact of DC-11bacterial culture filtrates against $A$. catenella}

To determine the effective algicidal threshold concentration of Arthrobacter sp. DC-11 against A. catenella, the alga was inoculated with the culture filtrates. Algicidal effects were observed in the control wells, which involved $100 \%$ PPES-II broth. Although all of the cells of A. catenella were still motile, their speed of motility decreased markedly within $3 \mathrm{~h}$ at low concentration of culture filtrates, $50 \mu \mathrm{l}$ added.
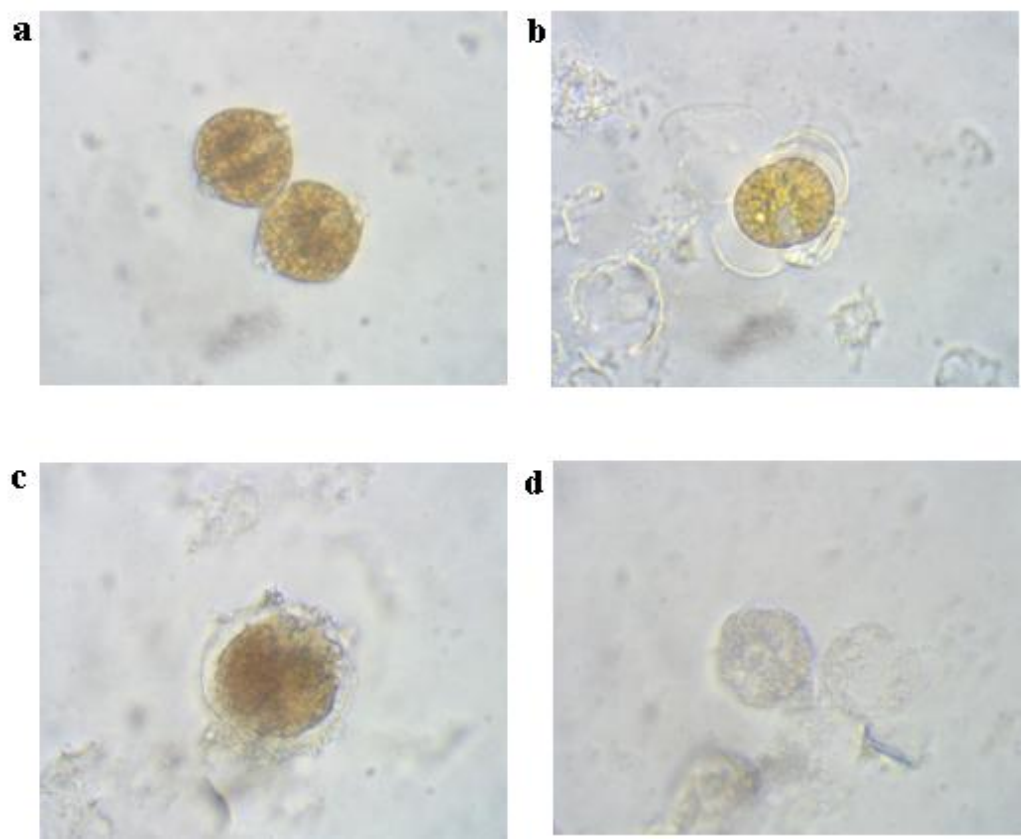

Fig. 2. Light microscopic observation of A. catenella, treated Arthrobacter sp. DC-11 culture filtrate: (a) normal cell, (b) cell walls becoming detached (ecdysis) after $3 \mathrm{~h}$, (c) release of cellular component after $9 \mathrm{~h}$, (d) destruction of cell contents and broken thecae after $48 \mathrm{~h}$.

The algicidal effect of Arthrobacter sp. DC-11 against A. catenella cells during the algicidal process was observed under light microscope (Fig. 2). When the algicidal bacterium took effect, the swimming movements of A. catenella cells were inhibited and cell walls detached from the main cellular bodies (Fig. 2b). 
With longer exposure time, A. catenella cells were disrupted. Subsequently, algal chloroplasts and cytoplasm also lost their integrity and decomposed (Fig. 2c), resulting in the appearance of abundant broken thecae (Fig. 2d).

\subsection{Impact of DC-43 bacterial culture filtrates against $A$. catenella}

To determine the effective algicidal threshold concentration of Brachybacterium sp. DC-43 against A. catenella, the alga was inoculated with different concentrations of the culture filtrates. Under the culture condition with $10 \%$ concentration in bacterial culture filtrate of total volume, algicidal activity was most significant. And the culture filtrates of Brachybacterium sp. DC-43 inhibited the growth of A. catenella in a concentration- and time-dependent manner. The algicidal effect of Brachybacterium sp. DC-43 against A. catenella cells during the algicidal process was observed under light microscope (Fig. 3). A. catenella cell shown same morphology change when Arthrobacter sp. DC11 was treated.
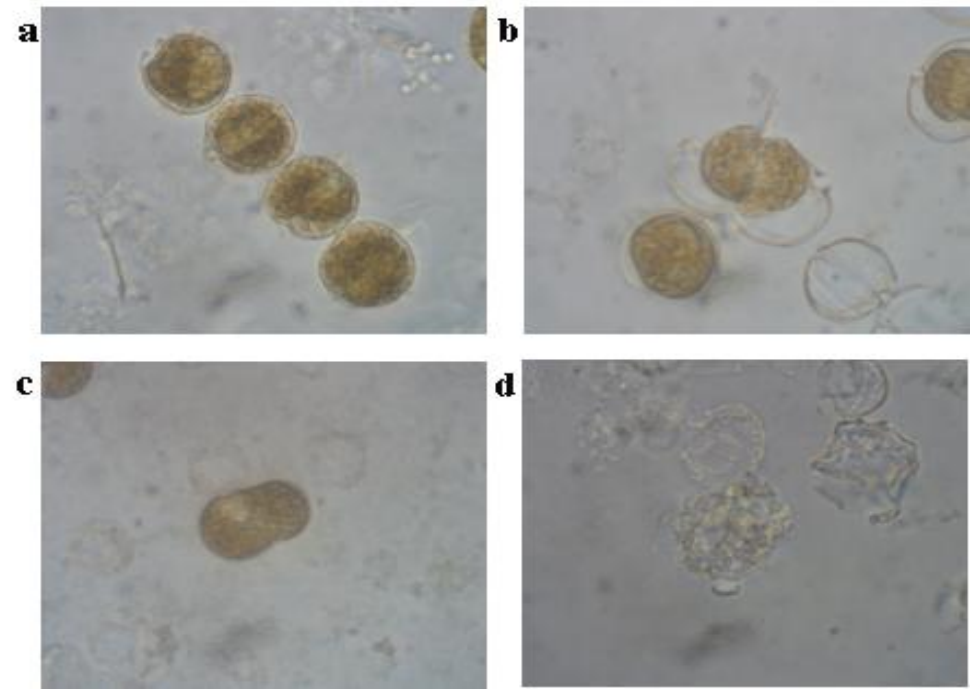

Fig. 3. Light microscopic observation of A. catenella, treated Brachybacterium sp. DC-43 culture filtrate: (a) normal cell; (b) cell walls becoming detached (ecdysis) after $1 \mathrm{~h}$; (c) release of cellular component after $7 \mathrm{~h}$; (d) broken thecae after $48 \mathrm{~h}$.

\subsection{Impact of DC-43 bacterial culture filtrates against $C$. polykrikoides}

The experiment for different concentrations of filtrates showed various levels of algicidal activity on the $C$. polykrikoides culture. C. polykrikoides was killed by high-concentration rather than low-concentration additions. A concentration of $<5 \%$ showed weak algicidal activity against $C$. polykrikoides.
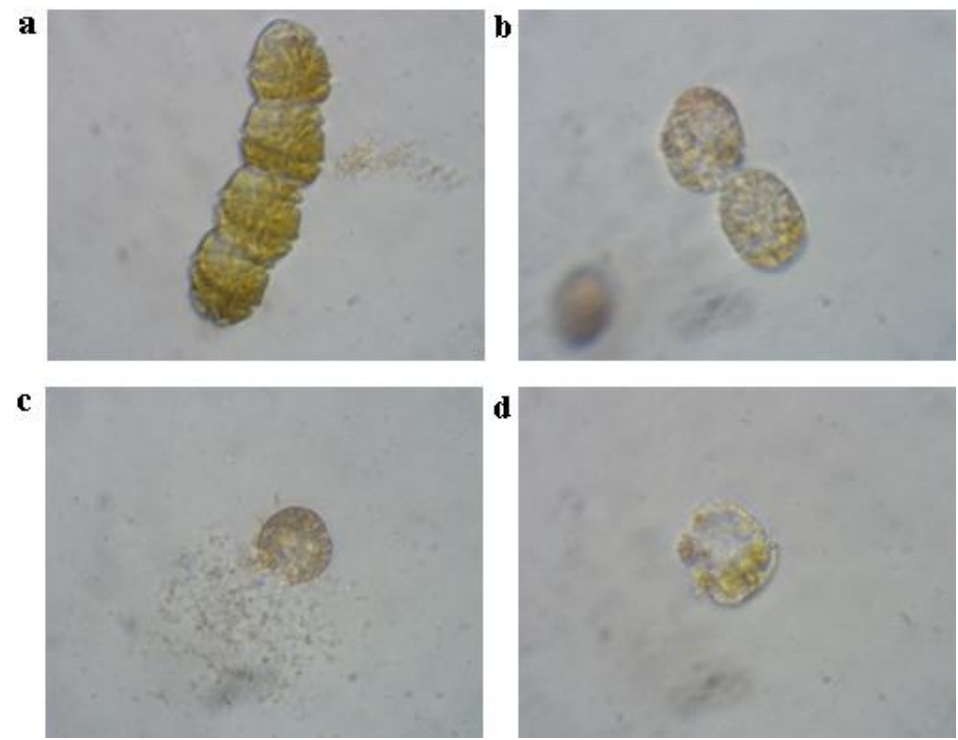

Fig. 4. Light microscopic observation of C. polykrikoides, treated Brachybacterium sp. DC-43 culture filtrate: (a) normal cell; (b) cells lost their motility and chains fell apart after $1 \mathrm{~h}$; (c) cells became rounded and busted after $7 \mathrm{~h}$; (d) lysis cell of $C$. polykrikoides within $48 \mathrm{~h}$. 
The algicidal effect of Brachybacterium sp. DC-43 against $C$. polykrikoides cells during the algicidal process was observed using light microscope (Fig. 4). When the algicidal bacterium took effect, $C$. polykrikoides cells lost their motility and chains fell apart within $1 \mathrm{~h}$ (Fig. 4b) and then $C$. polykrikoides cells became rounded of the resulting single cells or swelled after $7 \mathrm{~h}$ (Fig. 4c). Finally, . polykrikoides cells were bursted and degraded within 48 h (Fig. 4d).

\subsection{Impact of DC-49 bacterial culture filtrates against $C$. marina}

The experiment for different concentrations of culture filtrates (Bacillus sp. DC-49) showed various levels of algicidal activity on the $C$. marina culture. $C$. marina was killed by high-concentration rather than low-concentration additions. A concentration of $<5 \%$ showed weak algicidal activity against $C$. marina. Although all of the cells of $C$. marina remained motile, their speed of motility had decreased markedly within $3 \mathrm{~h}$, with a low concentration of culture filtrates (5\% added).
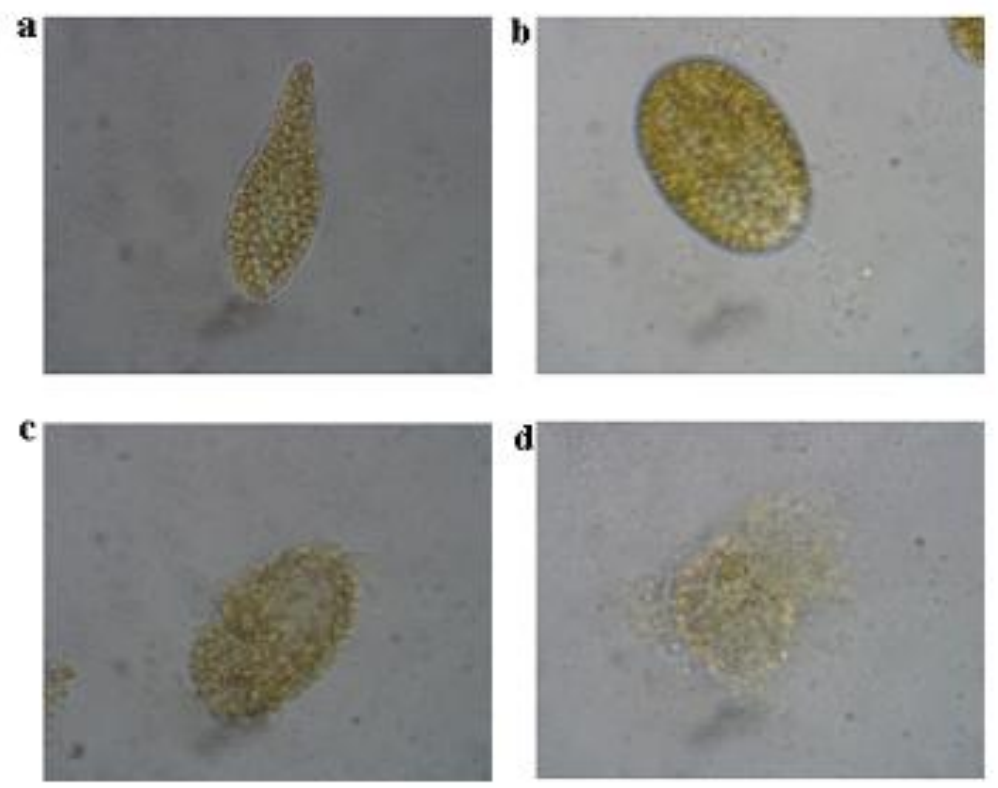

Fig. 5. Light microscopic observation of C. marina, treated Bacillus sp. DC-49 culture filtrate: (a) normal cell; (b) cell walls becoming swollen after $3 \mathrm{~h}$; (c) cell membrane rounded or disrupted after $6 \mathrm{~h}$; (d) release of cellular components and destruction of cell contents after $24 \mathrm{~h}$.

The algicidal effect of Bacillus sp. DC-49 against $C$. marina cells during the algicidal process was observed using light microscope (Fig. 5). When the algicidal bacterium took effect, the swimming movements of the C. marina cells became inhibited and the cell walls swollen, both within $1 \mathrm{~h}$ (Fig. 5b). With longer exposure time (i.e., $7 \mathrm{~h}$ ), C. marina cells became rounded or disrupted (Fig. 5c). Subsequently, cellular components also lost their integrity and decomposed, resulting in the appearance of abundant broken cellular components after $48 \mathrm{~h}$ (Fig. 5d).

\section{Discussion}

Algicidal bacteria are classified according to their algicidal mode, which can be either direct or indirect. In order to determinate algicidal mode, it was used commercially available tissue culture inserts. Each well, physically separated by a $0.4-\mu \mathrm{m}$ pore-size filter insert that allows algicides to diffuse across, was tested to determine mode of algicidal action (Lovejoy et al., 1998). The results, using tissue culture inserts, revealed that Arthrobacter sp. DC-11, Brachybacterium sp. DC-43, and Bacillus sp. DC-49 killed A. catenella, C. marina, and C. polykrikoides through algicide release as indirect attackers. Therefore, it was used culture filtrates in experiments to test algicidal activity.

Algicidal isolates were characterized according to their algicidal mechanisms, with approximately $70 \%$ showing an indirect mode and the remaining $(\sim 30 \%)$ requiring direct contact with the target prey (Mayali and Azam, 2004). Alternatively, algicidal bacteria exhibiting an indirect killing mechanism release dissolved algicides that effective in the absence of physical contact with the target host. Algicidal activity via released algicides clearly provides a competitive benefit to this segment of the microbial community (Roth et al., 2008).

In this study, the results showed that Arthrobacter sp. DC-11, Brachybacterium sp. DC-43 and Bacillus sp. DC-49 could be functioned as a red-tide controller. Recent works have been focusing on algicidal bacteria as controllers of water blooms, and so the identification and characterization of the molecules involved and responsible should us help understand the phenomenon within marine ecosystems. In the future, it will be worked to identify released algicides, to understand better how algicidal bacteria kill their prey. 


\section{Conclusion}

A total of 130 bacterial isolates were isolated from coastal water of Pusan in South Korea. Three isolates exhibited significant algicidal activity against three $\mathrm{HAB}$ species including Dinoflagellates A. catenella and C. polykrikoides, and RaphidophyceaeC. marina. The isolates, DC-11, DC-43, and DC-49 were identified as Arthrobacter sp., Brachybacterium sp., and Bacillus sp. by culture morphology and biochemical reactions, respectively. All of algicidal isolates killed $\mathrm{HAB}$ species through algicide release, as the indirect attackers. The culture filtrates of algicidal bacteria inhibited the growth of tested algal species in a concentration- and time-dependent manner. The most effective bacterium was Brachybacterium sp. DC-43.

In conclusion, these results suggest that algicidal marine bacteria could be potential biological agents for use in the control of HABs. Further studies are needed to identify the structure of the algicide.

\section{References}

Amaro, A.M., M.S. Fuentes, S.R. Ogalde, J.A. Venegas, and B.A. Suarez-Isla. 2005. Identification and characterization of potentially algal-lytic marine bacteria strongly associated with the toxic dinoflagellate Alexandrium catenella. J. Eukaryot. Microbiol. 52, 191-200.

Anderson, D.M., P. Hoagland, Y. Kaoru, and A.W. White. 2000. Estimated annual economic impacts from harmful algal blooms (HABs) in the United States. Woods Hole Oceanographic Institute Technical Report WHOI2000-11, Woods Hole, MA.

GEOHAB, 2001.Global Ecology and Oceanography of Harmful Algal Blooms, Science Plan.p. 87.In: Glibert, P., Pitcher, G. (eds.), SCOR and IOC, Baltimore and Paris.

Guillard, R.R.L. and J.H. Ryther. 1962. Studies of marine planktonic diatoms. I. Cyclotella nanaHustedt, and Detonulaconfervacea (Cleve).Gran.Can. J. Microbiol. 8, 229-235.

Hallegraeff, G.M. 1995. Harmful algal blooms: A global overview. p. 1-22. In: Hallegraeff G.M., Andeson D.M., Cembella A.D. (eds.), Manual on harmful marine microalgae, UNESCO, Paris, France.

Kang, Y.H., J.D. Kim, B.H. Kim, D.S. Kong, and M.S. Han. 2005. Isolation and characterization of a bio-agent antagonistic to diatom, Stephanodiscushantzschii. J. Appl. Microbiol. 98, 1030-1038.

Kim, C.S., S.G. Lee, C.K. Lee, H.G. Kim, and J. Jung. 1999. Reactive oxygen species as causative agents in the ichthyotoxicity of the red tide dinoflagellate Cochlodinium polykrikoides. J. Plankton Res. 21, 2105-2115.

Kim, J.D., B. Kim, and C.G. Lee. 2007. Alga-lytic of Pseudomonas fluorescens against the red tide causing marine alga Heterosigma akashiwo (Raphidophyceae). Biological Control 41, 296-303.

Lovejoy, C., J.P. Bowman, and G.M. Hallegraeff. 1998. Algicidal effects of a novel marine Pseudoalteromonas isolate (class Proteobacteria, gamma subdivision) on harmful algal bloom species of the genera Chattonella, Gymnodinium, and Heterosigma. Appl. Environ. Microbiol. 64, 2806-2813.

Mitsutani, A., I. Yamasaki, H. Kitaguchi, J. Kato, S. Ueno, and Y. Ishida. 2001. Analysis of algicidal proteins of a diatom-lytic marine bacterium Pseudoalteromonas sp. strain A25 by two-dimensional electrophoresis. Phycologia40, 286-291.

Nagasaki, K., M. Yamaguchi, and I. Imai. 2000. Algicidal activity of a killer bacterium against the red-tide dinoflagellate Heterocapsacircularisquama isolated from Ago Bay, Japan. Nippon Suisan Gakkaishi 66, 666673.

Rho, P.B., M.J. Twiner, C.M. Mikulski, A.B. Barnhorst, and G.J. Doucette. 2008. Comparative analysis of two algicidal bacteria active against the red tide dinoflagellate Karenia brevis. Harmful Algae 7, 682-691.

Sarthou, G., K.R. Timmermans, S. Blain, and P. Tréguer. 2005. Growth physiology and fate of diatoms in the ocean: a review. J. Sea Res. 53, 25-42.

Taga, N. 1968.Some ecological aspects of marine bacteria in the Kuroshio Current.Bull. Misaki Mar. Biol. 12, 65-76.

Su, J., X. Yang, T. Zheng, Y. Tian, N. Jiao, L. Cai, and H. Hong. 2007. Isolation and characterization of marine algicidal bacterium against the toxic dinoflagellate Alexandrium tamarense. Harmful Algae 6, 799-810.

Kitaguchi, H., N. Hiragushi, A. Mitsutani, M. Yamaguchi, and Y. Ishida. 2001. Isolation of an algicidal bacterium with activity against the harmful dinoflagellate Heterocapsacircularisquama(Dinophyceae). Phycologia40, 275279.

Nagayama, K., T. Shibata, K. Fujimoto, T. Honjo, and T. Nakamura. 2003. Algicidal effect of phlorotannins from the brown alga Eckloniakurome on red tide microalgae. Aquacult. 218, 601-611. 